\title{
Managing Cancer And Living Meaningfully (CALM): Phase 2 trial of a brief individual psychotherapy for patients with advanced cancer
}

\author{
Chris Lo, Sarah Hales, Judy Jung, Aubrey Chiu, Tania Panday, \\ Anne Rydall, Rinat Nissim, Carmine Malfitano, Danielle Petricone- \\ Westwood, Camilla Zimmermann, and Gary Rodin \\ Version Post-print/accepted manuscript \\ Citation Lo C, Hales S, Jung J, Chiu A, Panday T, Rydall A, Nissim R, Malfitano \\ (published version) C, Petricone-Westwood D,Zimmermann C, Rodin G. Managing Cancer \\ And Living Meaningfully (CALM): Phase 2 trial of abrief individual \\ psychotherapy for patients with advanced cancer. Palliative Medicine, \\ 2014 Mar; 28(3): 234-242. doi: 10.1177/0269216313507757
}

Copyright information Copyright (C) 2013 SAGE Publications. Reprinted by permission of SAGE Publications

How to cite TSpace items

\begin{abstract}
Always cite the published version, so the author(s) will receive recognition through services that track citation counts, e.g. Scopus. If you need to cite the page number of the author manuscript from TSpace because you cannot access the published version, then cite the TSpace version in addition to the published version using the permanent URI (handle) found on the record page.
\end{abstract}

This article was made openly accessible by $U$ of $T$ Faculty. Please tell us how this access benefits you. Your story matters. 


\section{Full citation and link to final published version:}

Lo C, Hales S, Jung J, Chiu A, Panday T, Rydall A, Nissim R, Malfitano C, PetriconeWestwood D, Zimmermann C, Rodin G. Managing Cancer And Living Meaningfully (CALM): Phase 2 trial of a brief individual psychotherapy for patients with advanced cancer. Palliative Medicine, 2014 Mar; 28(3):234-242. doi: 10.1177/0269216313507757 [Epub 2013 Oct 29] 
Managing Cancer And Living Meaningfully (CALM): phase 2 trial of a brief individual psychotherapy for patients with advanced cancer

Chris Lo, ${ }^{1,2}$ Sarah Hales, ${ }^{1,2}$ Judy Jung, ${ }^{1}$ Aubrey Chiu, ${ }^{1}$ Tania Panday, ${ }^{1}$ Anne Rydall, ${ }^{1}$ Rinat Nissim, ${ }^{1}$ Carmine Malfitano, ${ }^{1}$ Danielle Petricone-Westwood, ${ }^{1}$ Camilla Zimmermann, ${ }^{1,2}$ Gary Rodin ${ }^{1,2}$

${ }^{1}$ Department of Psychosocial Oncology and Palliative Care, Princess Margaret Cancer Centre, University Health Network, Toronto, Canada;

${ }^{2}$ Faculty of Medicine, University of Toronto, Toronto, Canada

Correspondence to: Dr Gary Rodin, Department of Psychosocial Oncology and Palliative Care, 16-724, Princess Margaret Cancer Centre, 610 University Avenue, Toronto, ON M5G 2M9, Canada; gary.rodin@uhn.ca 


\section{Abstract}

Background: Advanced cancer brings substantial physical and psychosocial challenges that may contribute to emotional distress and diminish wellbeing. In this study, we present preliminary data concerning the effectiveness of a new brief individual psychotherapy, Managing Cancer And Living Meaningfully (CALM), designed to help individuals cope with this circumstance. Aim: To test the feasibility and preliminary effectiveness of CALM to reduce emotional distress and promote psychological wellbeing and growth. Design: CALM is a brief, manualized, semistructured individual psychotherapy for patients with advanced cancer. This study employed a phase 2 intervention-only design. The primary outcome was depressive symptoms and the secondary outcomes were death anxiety, attachment security, spiritual wellbeing and psychological growth. These were assessed at 3 months (t1) and 6 months (t2). Multilevel regression was used to model change over time. Setting/participants: Fifty patients with advanced or metastatic cancer were recruited from the Princess Margaret Cancer Centre, Toronto, Canada. Results: Thirty-nine patients (78\%) were assessed at baseline, $24(48 \%)$ at $\mathrm{t} 1$, and $16(32 \%)$ at t2. Analyses revealed reductions over time in depressive symptoms, beta = $0.13, \mathrm{Cl}_{.95}(-0.23,-0.022)$, and death anxiety, beta $=-0.23, \mathrm{Cl} .95(-0.40,-0.061)$, and an increase in spiritual wellbeing, beta $=0.14, \mathrm{Cl}_{.95}(0.026,0.26)$. Conclusions: $\mathrm{CALM}$ may be a feasible intervention to benefit patients with advanced cancer. The results are encouraging despite attrition and small effect sizes, and support further study.

Keywords: affective symptoms, cancer, depression, palliative care, pilot trial, psychotherapy Word Count: 2973 


\section{Introduction}

Metastatic cancer is associated with numerous challenges, including multiple physical symptoms and progressive physical deterioration. These may trigger fears about dependency and the loss of autonomy, mortality and threat to the values that shape meaning in life. ${ }^{1}$

Disease burden and a variety of psychological and social factors have been associated with depression and demoralization, ${ }^{2,3}$ death anxiety, ${ }^{4}$ and the loss of a sense of meaning and purpose. ${ }^{5}$ While patients near the very end of life may be focused on life closure and death preparation, those with longer expected survival must balance the strains of illness and impending mortality with the goals of living in the present, a phenomenon that has been termed "double awareness". 6

In a longitudinal, mixed methods prospective study of patients with metastatic gastrointestinal and lung cancer with an expected survival of 12-18 months, more than one quarter of these individuals reported clinically significant depressive symptoms. ${ }^{3}$ We have proposed that these symptoms may be understood as a final common pathway of distress within the context of impending mortality, emerging in response to the interaction of disease-related, individual and

psychosocial factors. ${ }^{2,7-10}$ Prominent amongst these are the physical burden of disease, a relative lack of attachment security (i.e. confidence about the availability of supportive relationships and the capacity to make use of them for emotional support), self-esteem, and sense of meaning and faith..$^{2,3,11}$ 
Depressive symptoms and other forms of distress in advanced cancer, such as that related to dying and death, have been found to adversely affect quality of life, ${ }^{4,12}$ compliance with medical treatment, ${ }^{13}$ distress in caregivers ${ }^{9}$ and appropriate health care utilization. ${ }^{14}$ Unfortunately, distress may often go undetected and untreated in cancer patients. ${ }^{15,16}$ In order to improve these low rates of detection and treatment, routine computerized distress screening has been widely recommended as a standard in cancer care. ${ }^{17,18}$ Its benefit inevitably depends upon the systematic availability of effective interventions that follow detection. ${ }^{19}$ However, standardized and validated individual interventions tailored to alleviate distress in this unique population are limited. ${ }^{20-23}$ There is evidence that patients with advanced cancer tend to prefer psychological treatments over psychopharmacological ones. ${ }^{24,25}$ The former have the potential not only to relieve distress but also to promote psychological wellbeing and growth in attachment security and spiritual wellbeing, the latter referring to feelings of meaning, peace and faith. ${ }^{11,26,27}$ Although group therapy for cancer patients has received considerable attention in the literature, ${ }^{28-30}$ individual psychotherapy is preferred by patients with advanced disease and is often more feasible to deliver because sessions can be flexibly tailored to individual needs, taking into account other clinic appointments and fluctuations in health status. ${ }^{31-33}$

To address the gap in evidence-based, brief individual therapies designed for this population, we developed a manualized psychotherapeutic intervention to alleviate distress and to promote psychological wellbeing and growth in patients with metastatic cancer. This psychotherapy, entitled CALM (Managing Cancer And Living Meaningfully), ${ }^{34,35}$ was designed to 
address the specific problems and risk factors that affect mental health in this

circumstance. ${ }^{2,3,11}$ Although many psychotherapeutic modalities have been used to treat distress (e.g. cognitive behavioral therapy and interpersonal therapy), positive outcomes and sustained improvement may be most likely when treatment is also directed at etiological and pathogenic factors. ${ }^{36}$ A conceptual model of the outcomes targeted by CALM and their interrelationships in the context of advanced cancer are shown in Figure 1.

CALM addresses four main domains that are relevant to patients with advanced disease: symptom control and communication with health care providers; self-concept and relations with close others; spiritual wellbeing and the values and beliefs that provide meaning and purpose in life; and preparing for the future, sustaining hope, and facing mortality. This approach provides support and reflective space for the processing of thoughts and emotions and facilitates the resolution of practical and existential questions that face individuals with metastatic disease. It shares features with manualized supportive expressive, ${ }^{37-42}$ cognitive existential, ${ }^{43,44}$ and meaning-centered ${ }^{45}$ group psychotherapies applied to patients with advanced and terminal disease.

The purpose of the present study was to examine the feasibility and preliminary effectiveness of CALM. We recruited individuals with advanced or metastatic cancer to pilot test recruitment, treatment and follow-up procedures prior to the initiation of a large randomized controlled trial (RCT) of CALM. We hypothesized that there would be a reduction in depressive symptoms and 
death anxiety over time, and an increase in attachment security, spiritual wellbeing and psychological growth. The primary outcome was depressive symptoms, with the remaining outcomes being secondary.

\section{Methods}

\section{Setting, Participants and Procedure}

This study was approved by the Research Ethics Board of the University Health Network.

Recruitment occurred from January 2009 to May 2011 at the Princess Margaret Cancer Centre, part of University Health Network, in Toronto, Canada. Psychosocial services are provided by psychiatrists, social workers, psychologists and spiritual care experts at the Princess Margaret. Referral to psychosocial oncology occurs in approximately one third of patients with advanced cancer, of whom one third are seen in psychiatry or psychology consultations. ${ }^{16}$ The majority of psychosocial care involves brief supportive interactions and instrumental assistance, without delivery of psychotherapy. The palliative care program consists of a 12-bed acute palliative care unit, an inpatient consultation service and outpatient pain and palliative care clinics. Although symptom distress is routinely addressed by palliative care staff, they are not trained to deliver specialized psychotherapeutic interventions.

The study was a phase 2 trial involving an intervention-only design. ${ }^{46}$ Our reporting is consistent with the Transparent Reporting of Evaluations with Nonrandomized Designs (TREND) guidelines ${ }^{47}$ amended for this design. The primary outcome was depressive symptoms and the 
secondary outcomes were death anxiety, attachment security, spiritual wellbeing and psychological growth. Eligible patients were at least 18 years of age; had a confirmed diagnosis of Stage IV cancer, or Stage III lung cancer due to its short prognosis; did not have cognitive impairment documented in their medical chart; were sufficiently fluent in English to provide informed consent and to participate in the intervention; and were interested in individual psychotherapy to assist in their coping with disease. A research assistant approached potential participants during routine visits to clinics in Medical Oncology or Psychosocial Oncology at the Princess Margaret. The research assistant described the intervention to patients and obtained written informed consent from those who agreed to participate in this study. Participants were then asked to give basic medical and demographic information and to complete self-report questionnaires at the start of therapy (t0) and at 3 months (t1) and 6 months (t2). One hundred forty-one patients were identified for approach concerning study participation, of whom 50 (35\%) consented (see Figure 2). No demographic data is available concerning those who did not consent.

\section{Intervention}

Managing Cancer And Living Meaningfully (CALM) is a brief, manualized, semi-structured, individual psychotherapy designed for patients with advanced cancer to relieve distress and promote wellbeing and growth. ${ }^{34,35}$ It was developed from empirical data, clinical observations, and the foundations of relational, ${ }^{48}$ attachment $^{49}$ and existential ${ }^{50}$ theory. CALM includes 3-8 individual sessions delivered over 6 months with each session lasting 60 minutes. The sessions 
address four domains: 1) symptom management and communication with health care providers; 2 ) changes in self and relations with close others; 3) spiritual wellbeing, or the sense of meaning and purpose; and 4) preparing for the future, sustaining hope and facing mortality. All domains are explored with every patient, but discussion of each domain varies based on the concerns most relevant to each person. Each participant's primary caregiver (i.e. spouse or partner, adult son or daughter) is offered the opportunity to participate in one or more of the therapy sessions, as deemed appropriate by the therapist and with the patient's permission. Caregivers provided informed consent prior to participating in therapy sessions.

CALM was delivered by 6 master's level social workers, 2 psychiatrists, and 1 oncologist in the Department of Psychosocial Oncology and Palliative Care at the Princess Margaret Cancer Centre. Each therapist had over 5 years of experience working with cancer patients prior to CALM training. Therapists were deemed competent to provide CALM after attending a fourhour training session and receiving 15 hours of case supervision from the clinician investigators who developed the intervention (GR and SH). Continuing weekly group supervision sessions for case formulation and discussion ensured treatment adherence and skill development throughout the course of study.

\section{Measures}

Medical and demographic data were obtained from participants at recruitment and also extracted from medical charts. 
Depressive symptoms were measured using the validated Patient Health Questionnaire-9 (PHQ9), ${ }^{51}$ a 9-item scale that has been widely used in cancer. ${ }^{52}$ The scale produces a summed score ranging from 0-27, with higher scores indicating greater depressive symptoms.

Spiritual wellbeing was measured using the 12-item Functional Assessment of Chronic Illness Therapy-Spiritual Wellbeing Scale (FACIT-Sp-12), validated for use in cancer. ${ }^{26}$ This instrument assesses aspects of spiritual wellbeing, including a sense of meaning and purpose, feelings of peace and harmony, and feelings of comfort and strength derived from one's faith or spiritual beliefs. The scale generates an overall spiritual wellbeing score that may range from 0-48. Higher values indicate greater wellbeing.

Death anxiety was measured using the 15 -item Death and Dying Distress Scale (DADDS), which was designed and validated for use in advanced cancer. ${ }^{4}$ This scale asks individuals to rate how distressed they felt over the past two weeks about specific thoughts or concerns that may be experienced by patients with life-threatening illness. The items capture anxieties about the loss of time and opportunity, the process of dying and death, and the anticipated impact of the patient's death on others. Scores may range from 0-75, with higher scores indicating greater distress about death and dying. 
Attachment security in close relationships was assessed using the 16-item Modified Experiences in Close Relationships scale (ECR-M16), validated in advanced cancer. ${ }^{53}$ It has two subscales, one of which assesses anxious attachment (i.e. fear of abandonment) and the other avoidant attachment (i.e. defensive independence and discomfort with closeness). Subscale scores may range from 8-56, with higher scores indicating greater attachment anxiety or avoidance.

Psychological growth over the preceding 6 months was measured using the 21-item Posttraumatic Growth Inventory (PTGI), ${ }^{54}$ previously used in cancer to assess positive psychological changes that occur following trauma. ${ }^{55}$ The PTGI provides a total score based on the perception of new possibilities and spiritual change, and growth in inner strength, relations with others, and greater appreciation of life following trauma. Scores may range from 0-105, with higher values indicating greater growth.

\section{Statistical Analysis}

To determine whether there were significant changes in outcomes over time, multilevel modeling ${ }^{56}$ was used to predict the trajectory of each variable as a function of the number of months since the start of CALM therapy. An advantage of multilevel models over traditional repeated measures analyses is that they can utilize data from subjects with missing longitudinal assessments in the estimation of effects and can accommodate differences in the timing of assessments. In our models, patient was specified as the higher level with repeated measures as the lower level. Patient intercepts were set as random effects, but the effect of time was not 
because preliminary model fitting indicated that there was negligible variation. Estimates of change over time corrected for initial baseline scores.

\section{Results}

Of 50 patients consented, 41 (82\%) provided demographic information (see Table 1). Figure 2 provides participation details and assessment completion rates. The $\mathrm{t} 1$ assessment was taken on average 3.6 months, $\mathrm{SD}=0.75$, after the t0 assessment and the t2 assessment 7.2 months, $S D=1.4$, after t0. At the t1 assessment, 26 of 50 patients (52\%) were lost to follow-up, and at the $\mathrm{t} 2$ assessment, 34 of 50 patients (68\%) were lost to follow-up.

See Table 1 for information about the number of CALM sessions received by patients. Thirtyeight percent of the sample received $3-5$ sessions, and $20 \%$ of patients received $6-8$ sessions. Greater frequency of CALM sessions was associated with study completion at $t 2, F(1,37)=9.22$, $p=0.004$. Individuals who completed the study had a mean of 5 CALM sessions, $S D=1.4$, compared to a mean of 3 sessions, $\mathrm{SD}=1.9$, for those who did not complete the study. Caregivers attended CALM therapy sessions with the patient in 13 out of 50 cases, or $26 \%$ of the sample.

In Table 2, we present the means of each outcome by assessment. See Table 3 for the initial estimates of the variation found at the patient level and the level of the repeated assessments before entry of the explanatory effect of time. For most variables, there was more variation 
between patients than within patients in their repeated measures. The exception was death anxiety, where $52 \%$ of the variation was attributable to within-patient changes in repeated assessments.

Table 4 describes the regression results in which outcomes were regressed on time. There were statistically significant changes in depressive symptoms, death anxiety and spiritual wellbeing. The largest effect was found for death anxiety, which declined by about one and one third points per month. Depressive symptoms declined by about one quarter of a point each month and spiritual wellbeing increased by about half a point each month. The magnitude of the standardized regression estimates indicate that these are small effect sizes. ${ }^{57}$ There remained significant residual variance unexplained by the effect of time in the repeated measurement of death anxiety, residual = 126; depressive symptoms, residual = 5; and spiritual wellbeing, residual $=20$, all $p^{\prime} s<0.0001$

Lastly, we conducted a sub-analysis of only individuals who had completed at least 3 sessions of CALM therapy. The reductions over time in depressive symptoms, $p=0.02$, and death anxiety, $p$ $=0.02$, were robust although the effect on spiritual wellbeing was not, $p=0.06$.

\section{Discussion}

In this phase 2, intervention-only study with follow-up assessments at 3 and 6 months, we recruited a small sample of patients with advanced or metastatic cancer to test the feasibility 
and preliminary effectiveness of CALM, prior to initiation of an RCT. Attrition was high, with only $58 \%$ of patients completing at least 3 sessions of CALM, $48 \%$ completing the t1 follow-up assessment, and $32 \%$ completing the t 2 follow-up. Study completion was associated with longer duration of therapy, which may be because better physical health allowed patients to complete both clinical and research components of this study. The most common known reasons for loss to follow-up were death and physical decline, reported by $25 \%$ of lost participants at $\mathrm{t} 1$ and $70 \%$ of lost participants at $\mathrm{t} 2$. This attrition rate highlights the difficulty recruiting, treating and retaining a population with progressive physical impairment and a limited life expectancy. Efforts are now being made to recruit patients closer to the time of detection of metastases or of advanced disease. This may help to ensure that the intervention is delivered to patients who are facing the problems of advanced disease and impending mortality, but are still well enough to engage in, complete, and benefit from a brief course of outpatient psychotherapy.

Despite substantial attrition, we were able to detect small but statistically significant changes over time in the outcomes. Depressive symptoms and death anxiety were found to decline over time and spiritual wellbeing to improve. The impact on depressive symptoms in this population is notable in view of the usual increase in depressive symptoms that tends to occur in this population with closer proximity to death. ${ }^{3}$ The increase of spiritual wellbeing is compatible with the view that the relief of distress and the creation of reflective space contributed to a greater sense of meaning and peace. The largest effect was found for death anxiety. Despite its 
relevance for such patients, ${ }^{58}$ death anxiety has rarely been studied as an empirical outcome in populations near the end of life. This omission may be due, in part, to the perceived difficulty assessing death-related fears and to the lack of specific measurement tools, such as the Death and Dying Distress Scale, tailored to the context of advanced cancer. ${ }^{4}$ Although encouraging, the patterns of change that we have observed following CALM therapy require confirmation in a randomized controlled study to be certain that they can be attributed to the effects of the intervention.

Overall, this phase 2 trial suggests that CALM is feasible to deliver to patients with advanced cancer and that benefit can be demonstrated using the selected quantitative outcomes. These findings complement previous qualitative data regarding the acceptability and impact of CALM. $^{35}$ In that qualitative research, participants described CALM as a unique opportunity to process the experience of advanced cancer that gave permission to explore issues of death and dying. Participants reported that these discussions helped them to better plan for and manage illness-related needs and to resolve interpersonal problems that arose in the context of advanced disease. No risks or concerns were identified by patients in that study.

There are a number of limitations to this phase 2 study. The sample size was small and there was substantial loss to follow-up, which may have biased the regression estimates. The sample consisted of mostly Caucasian or European, English speaking, and relatively well-educated patients. The lack of randomization and a control group constrains our ability to ascertain 
whether the observed changes over time can be attributed to CALM or to other factors. Patients in this study were not selected based on elevated distress scores, which may have reduced the ability to show benefit on the outcomes. Those who did participate were motivated to some extent to discuss their thoughts and feelings and to desire help related to their illness.

\section{Conclusions}

CALM holds promise as a brief intervention to relieve distress and promote psychological wellbeing and growth in patients with advanced cancer. Its delivery requires training and ongoing supervision of psychosocial oncology clinicians to support them in this emotionally challenging work and to ensure treatment integrity. The preliminary results are encouraging and support the RCT being conducted at the Princess Margaret Cancer Centre in Toronto, Canada. Pilot trials of CALM are now underway, or in the planning phase, in Germany, Italy, Taiwan and the United Kingdom.

\section{What is already known about the topic?}

- Psychological distress is common in advanced disease

- Psychotherapeutic interventions may be effective in advanced disease, although most research has evaluated those in a group format

- Tailored individual interventions may have unique practical and clinical value in advanced disease, but research on such interventions has been lacking 


\section{What this paper adds?}

- Managing Cancer and Living Meaningfully (CALM), a brief, manualized, individual psychotherapeutic intervention focused on four broad domains relevant to advanced cancer, can be successfully delivered to this population

- Participation in CALM is associated at three and six-month follow-up with a significant reduction in symptoms of depression and death anxiety and with significant growth in spiritual wellbeing

\section{Implications for practice, theory or policy}

- The results of this phase II trial of CALM justify the undertaking of larger randomized controlled trials that are now underway in Canada and Europe

- Pilot studies are needed and now underway in Canada, Europe and Asia to assess the feasibility of training therapists from multiple disciplines to deliver CALM in diverse clinical settings

- CALM is a therapeutic intervention that has the potential for international application as a psychological dimension of early palliative care in patients with advanced disease 
Funding: This study was funded by a research grant from the University Health Network Department of Psychiatry (SH, CL, GR) and partly funded by the Canadian Institutes of Health Research (CIHR \#MOP 106473). This research was also supported by the Princess Margaret Cancer Foundation Hertz Centre Fund, the Campbell Family Cancer Research Institute and the Ontario Cancer Institute at Princess Margaret Cancer Centre, and by the Ontario Ministry of Health and Long Term Care (OMOHLTC). The views expressed do not necessarily reflect those of the OMOHLTC. Dr. Rodin is also supported by the University of Toronto/University Health Network Harold and Shirley Lederman Chair in Psychosocial Oncology and Palliative Care. The funders had no role in the final design, analysis and writing of this study.

Conflict of Interest: None declared.

Acknowledgements: We would like to thank the participants for their time and effort to complete this study. We also thank our research staff, including Leanne Ferreira, and our CALM therapists, Robin Forbes, Valerie Heller, Cheryl Kanter, Rhonda Kibrick-Lazear, Fiorella Lubertacci, Jenny Shaheed, Dr. Robert Buckman, for their valuable contributions to this study. 


\section{References}

1. Rodin G. Individual psychotherapy for the patient with advanced disease. In: Chochinov $\mathrm{H}$ and Breitbart W (eds) Handbook of Psychiatry in Palliative Medicine. London: Oxford University, 2009, pp. 443-453.

2. Rodin G, Lo C, Mikulincer M, et al. Pathways to distress: the multiple determinants of depression, hopelessness and the desire for hastened death in metastatic cancer patients. Soc Sci Med 2009; 68: 562-569.

3. Lo C, Zimmermann C, Rydall AC, et al. Longitudinal study of depressive symptoms in patients with metastatic gastrointestinal and lung cancer. J Clin Oncol 2010; 28: 30843089.

4. Lo C, Hales S, Zimmermann C, et al. Measuring death-related anxiety in advanced cancer: preliminary psychometrics of the Death and Dying Distress Scale. J Pediatr Hematol/Oncol 2011; 33 Suppl 2: S140-S145.

5. Lo C, Zimmermann C, Gagliese L, et al. Sources of spiritual well-being in advanced cancer. BMJ Support Palliat Care 2011; 1: 149-153.

6. Rodin $\mathrm{G}$ and Zimmermann C. Psychoanalytic reflections on mortality: a reconsideration. J Am Acad Psychoanal Dyn Psychiatry 2008; 36: 181-196.

7. Rodin G, Walsh A, Zimmermann C, et al. The contribution of attachment security and social support to depressive symptoms in patients with metastatic cancer.

Psychooncology 2007; 16: 1080-1091.

8. Rodin G, Zimmermann C, Rydall A, et al. The desire for hastened death in patients with metastatic cancer. J Pain Symptom Manage 2007; 33: 661-665.

9. Lo C, Hales S, Braun M, et al. Couples facing advanced cancer: examination of an interdependent relational system. Psychooncology Epub ahead of print 29 Apr 2013. DOI: 10.1002/pon.3289

10. Nissim R, Gagliese $L$ and Rodin $G$. The desire for hastened death in individuals with advanced cancer: a longitudinal qualitative study. Soc Sci Med 2009; 69: 165-171.

11. Lo C, Zimmermann C, Gagliese L, et al. Sources of spiritual well-being in advanced cancer. BMJ Support Palliat Care 2011; 1: 149-153. 
12. Grassi L, Indelli M, Marzola M, et al. Depressive symptoms and quality of life in homecare assisted cancer patients. J Pain Symptom Manage 1996; 12: 300-307.

13. Colleoni M, Mandala M, Peruzzotto $G$, et al. Depression and degree of acceptance of adjuvant cytotoxic drugs. Lancet 2000; 356: 1326-1327.

14. Prieto JM, Blanch J, Atala J, et al. Psychiatric morbidity and impact on hospital length of stay among hematologic cancer patients receiving stem-cell transplantation. J Clin Oncol 2002; 20: 1907-1917.

15. Fallowfield $L$, Ratcliffe $D$, Jenkins $V$, et al. Psychiatric morbidity and its recognition by doctors in patients with cancer. Br J Cancer 2001; 84: 1011-1015.

16. Ellis J, Lin J, Walsh A, et al. Predictors of referral for specialized psychosocial oncology care in patients with metastatic cancer: the contributions of age, distress, and marital status. J Clin Oncol 2009; 27: 699-705.

17. NICE (National Institute for Health and Clinical Excellence). Cancer service guidance: supportive and palliative care. Improving supportive and palliative care for adults with cancer, March 2004, http://www.nice.org.uk/CSGSP (accessed July 24, 2013).

18. Turner J, Zapart S, Pedersen K, et al. Clinical practice guidelines for the psychosocial care of adults with cancer. Psychooncology 2005; 14: 159-173.

19. Palmer SC and Coyne JC. Screening for depression in medical care: pitfalls, alternatives, and revised priorities. J Psychosom Res 2003; 54: 279-287.

20. Ando M, Morita T, Akechi T, et al. Efficacy of short-term life-review interviews on the spiritual well-being of terminally ill cancer patients. J Pain Symptom Manage 2010; 39: 993-1002.

21. Chochinov HM, Kristjanson $\amalg$, Breitbart W, et al. Effect of dignity therapy on distress and end-of-life experience in terminally ill patients: a randomised controlled trial. Lancet Oncol 2011; 12: 753-762.

22. LeMay K and Wilson KG. Treatment of existential distress in life threatening illness: a review of manualized interventions. Clin Psychol Rev 2008; 28: 472-493. 
23. Henry M, Cohen SR, Lee $\mathrm{V}$, et al. The Meaning-Making intervention (MMi) appears to increase meaning in life in advanced ovarian cancer: a randomized controlled pilot study. Psychooncology 2010; 19: 1340-1347.

24. Akechi T, Okuyama T, Onishi J, et al. Psychotherapy for depression among incurable cancer patients. Cochrane Database Syst Rev 2008 Apr 16; (2):CD005537. DOI: 10.1002/14651858.CD005537.pub2.

25. Barbui C, Cipriani A, Patel V, et al. Efficacy of antidepressants and benzodiazepines in minor depression: systematic review and meta-analysis. Br J Psychiatry 2011; 198: 1116.

26. Canada AL, Murphy PE, Fitchett G, et al. A 3-factor model for the FACIT-Sp. Psychooncology 2008; 17: 908-916.

27. Block SD. Perspectives on care at the close of life. Psychological considerations, growth, and transcendence at the end of life: the art of the possible. JAMA 2001; 285: 28982905.

28. Goodwin PJ, Leszcz M, Ennis M et al. The effect of group psychosocial support on survival in metastatic breast cancer. N Engl J Med 2001; 345: 1719-1726.

29. Kissane D. Beyond the psychotherapy and survival debate: the treatment challenge of social disparity, depression and treatment adherence in psychosocial cancer care. Psychooncology 2009; 18: 1-5.

30. Edelman S, Bell DR and Kidman AD. A group cognitive behaviour therapy programme with metastatic breast cancer patients. Psychooncology 1999; 8: 295-305.

31. Clark MM, Bostwick JM and Rummans TA. Group and individual treatment strategies for distress in cancer patients. Mayo Clin Proc 2003; 78: 1538-1543.

32. Sherman AC, Pennington J, Latif $U$, et al. Patient preferences regarding cancer group psychotherapy interventions: a view from the inside. Psychosomatics 2007; 48: 426-432.

33. Cuijpers $P$, van Straten $A$ and Warmerdam L. Are individual and group treatments equally effective in the treatment of depression in adults? A meta-analysis. Eur J Psychiatry 2008; 22: 38-51. 
34. Hales S, Lo C and Rodin G. Managing Cancer And Living Meaningfully (CALM) treatment manual: an individual psychotherapy for patients with advanced cancer. (C2010, Princess Margaret Hospital, University Health Network, Toronto, Canada.

35. Nissim R, Freeman E, Lo C, et al. Managing Cancer And Living Meaningfully (CALM): a qualitative study of a brief individual psychotherapy for individuals with advanced cancer. Palliat Med 2012; 26: 713-721.

36. Luyten P, Blatt SJ, van Houdenhove BJ, et al. Depression research and treatment: are we skating to where the puck is going to be? Clin Psychol Rev 2006; 26: 985-999.

37. Spiegel D, Bloom JR and Yalom I. Group support for patients with metastatic cancer: a randomized outcome study. Arch Gen Psychiatry 1981; 38: 527-533.

38. Spiegel D, Morrow GR, Classen C, et al. Group psychotherapy for recently diagnosed breast cancer patients: a multicenter feasibility study. Psychooncology 1999; 8: 482-493.

39. Classen C, Butler LD, Koopman C, et al. Supportive-expressive group therapy and distress in patients with metastatic breast cancer: a randomized clinical intervention trial. Arch Gen Psychiatry 2001; 58: 494-501.

40. Giese-Davis J, Koopman C, Butler LD, et al. Change in emotion-regulation strategy for women with metastatic breast cancer following supportive-expressive group therapy. $J$ Consult Clin Psychol 2002; 70: 916-925.

41. Bordeleau L, Szalai JP, Ennis M, et al. Quality of life in a randomized trial of group psychosocial support in metastatic breast cancer: overall effects of the intervention and an exploration of missing data. J Clin Oncol 2003; 21: 1944-1951.

42. Weiss JJ, Mulder CL, Antoni MH, et al. Effects of a supportive-expressive group intervention on long-term psychosocial adjustment in HIV-infected gay men. Psychother Psychosom 2003; 72: 132-140.

43. Kissane DW, Bloch S, Smith GC, et al. Cognitive-existential group psychotherapy for women with primary breast cancer: a randomised controlled trial. Psychooncology 2003; 12: $532-546$.

44. Kissane DW, Love A, Hatton A, et al. Effect of cognitive-existential group therapy on survival in early-stage breast cancer. J Clin Oncol 2004; 22: 4255-4260.

45. Breitbart W, Gibson C, Poppito SR, et al. Psychotherapeutic interventions at the end of 
life: a focus on meaning and spirituality. Can J Psychiatry 2004; 49: 366-372.

46. Des Jarlais DC, Lyles C, Crepaz N, and the TREND Group. Nonrandomized evaluations of behavioral and public health interventions: the TREND statement. Am J Public Health 2004; 94: 361-366.

47. Stanley K. Design of randomized controlled trials. Circulation 2007; 115: 1164-1169.

48. Mitchell SA. Relational concepts in psychoanalysis: an integration. Cambridge, MA: Harvard, 1988.

49. Bowlby J. Attachment. New York, NY: Basic Books, 1982.

50. Yalom ID. Existential psychotherapy. New York, NY: Basic Books, 1980.

51. Kroenke K, Spitzer RL and Williams JBW. The PHQ-9: validity of a brief depression severity measure. J Gen Intern Med 2001; 16: 606-613.

52. Thekkumpurath P, Walker J, Butcher I, et al. Screening for major depression in cancer outpatients: the diagnostic accuracy of the 9-item patient health questionnaire. Cancer 2011; 117: 218-227.

53. Lo $\mathrm{C}$, Walsh A, Mikulincer M, et al. Measuring attachment security in patients with advanced cancer: psychometric properties of a modified and brief Experiences in Close Relationships scale. Psychooncology 2009; 18: 490-499.

54. Tedeschi RG and Calhoun LG. The Posttraumatic Growth Inventory: measuring the positive legacy of trauma. J Trauma Stress 1996; 9: 455-471.

55. Stanton AL, Bower JE and Low CA. Posttraumatic growth after cancer. In: Calhoun LG and Tedeschi RG (eds) Handbook of posttraumatic growth. Mahwah, NJ: Lawrence Erlbaum, 2006, pp. 138-175.

56. Singer J. Using SAS PROC MIXED to fit multilevel models, hierarchical models, and individual growth models. J Educ Behav Stat 1998; 24: 323-355.

57. Cohen J. A power primer. Psychol Bull 1992; 112: 155-159.

58. Hales S, Zimmermann C and Rodin G. The quality of dying and death. Arch Intern Med 2008; 168: 912-918. 
Table 1. Sample characteristics and dosages of CALM therapy delivered.

\begin{tabular}{|c|c|c|}
\hline Variable & Mean (SD) or Percent (N) & Q1-Median-Q \\
\hline \multicolumn{3}{|l|}{ Demographics $(\mathrm{N}=41)$} \\
\hline Age in years & $52(12)$ & $47-51-62$ \\
\hline Illness duration in years & $3.0(3.6)$ & $0.72-1.5-3.5$ \\
\hline Female & $76 \%(31)$ & \\
\hline Married/Common-law & $68 \%(28)$ & \\
\hline \multicolumn{3}{|l|}{ Education } \\
\hline High School & $5 \%(2)$ & \\
\hline College & $27 \%(11)$ & \\
\hline University & $49 \%(20)$ & \\
\hline Post-graduate & $20 \%(8)$ & \\
\hline \multicolumn{3}{|l|}{ Ethnicity } \\
\hline Canadian & $32 \%(13)$ & \\
\hline Caucasian & $24 \%(10)$ & \\
\hline Western European & $22 \%(9)$ & \\
\hline Eastern European & $10 \%(4)$ & \\
\hline Asian & $7 \%(3)$ & \\
\hline Other & $5 \%(2)$ & \\
\hline \multicolumn{3}{|l|}{ Diagnosis Group } \\
\hline Gastrointestinal & $24 \%(10)$ & \\
\hline Gynecological & $24 \%(10)$ & \\
\hline Breast & $10 \%(4)$ & \\
\hline Lung & $10 \%(4)$ & \\
\hline Genitourinary & $7 \%(3)$ & \\
\hline Lymphoma & $7 \%(3)$ & \\
\hline Sarcoma & $7 \%(3)$ & \\
\hline Melanoma & $5 \%(2)$ & \\
\hline Endocrine & $2 \%(1)$ & \\
\hline Myeloma & $2 \%(1)$ & \\
\hline \multirow{2}{*}{\multicolumn{3}{|c|}{$\begin{array}{l}\text { Dosages of CALM therapy } \\
\text { delivered to patients }(N=50)\end{array}$}} \\
\hline & & \\
\hline Zero sessions & $8(16 \%)$ & \\
\hline One session & $7(14 \%)$ & \\
\hline Two sessions & $6(12 \%)$ & \\
\hline Three sessions & $9(18 \%)$ & \\
\hline Four sessions & $8(16 \%)$ & \\
\hline Five sessions & $2(4 \%)$ & \\
\hline Six sessions & $6(12 \%)$ & \\
\hline Seven sessions & $2(4 \%)$ & \\
\hline Eight sessions & $2(4 \%)$ & \\
\hline
\end{tabular}


Table 2. Mean outcome values (and standard deviations) by assessment.

\begin{tabular}{llll} 
Outcome & t0 assessment $^{\mathrm{a}}$ & $\mathrm{t} 1$ assessment $^{\mathrm{b}}$ & $\mathrm{t}^{2}$ assessment $^{\mathrm{c}}$ \\
\hline Depressive symptoms & $8.7(6.0)$ & $7.7(5.0)$ & $6.9(5.3)$ \\
Spiritual wellbeing & $29(10)$ & $33(10)$ & $31(9.2)$ \\
Death anxiety & $37(17)$ & $32(17)$ & $29(14)$ \\
Avoidant attachment & $23(9.7)$ & $21(10)$ & $21(7.1)$ \\
Anxious attachment & $24(10)$ & $20(9.3)$ & $23(9.3)$ \\
Psychological growth & $57(20)$ & $61(18)$ & $61(20)$
\end{tabular}

${ }^{a} n=39$ with the exception of psychological growth, where $n=38$.

${ }^{b} n=24$.

${ }^{c} n=15$ with the exception of depressive symptoms, where $n=16$. 
Table 3. Variance estimates at the patient level (i.e. between-patients) and at the level of repeated measures (i.e. within-patients).

\begin{tabular}{lll} 
& Repeated \\
Outcome & Patient & Measures \\
\hline Depressive symptoms & 30 & 6 \\
Spiritual wellbeing & 89 & 22 \\
Death anxiety & 134 & 148 \\
Avoidant attachment & 70 & 25 \\
Anxious attachment & 64 & 35 \\
Psychological growth & 249 & 153
\end{tabular}

Note. All estimates were significant at $p \leq 0.007$. 
Table 4. Regression estimates of the effect of time on each outcome.

\begin{tabular}{lllll} 
Outcome & $\mathrm{B}$ & beta & beta $\mathrm{Cl}_{0.95}$ & $p$-value \\
\hline Depressive symptoms & -0.24 & -0.13 & $-0.23,-0.022$ & 0.019 \\
Spiritual wellbeing & 0.49 & 0.14 & $0.026,0.26$ & 0.017 \\
Death anxiety & -1.31 & -0.23 & $-0.40,-0.061$ & 0.009 \\
Avoidant attachment & -0.38 & -0.12 & $-0.25,0.017$ & 0.09 \\
Anxious attachment & -0.20 & -0.059 & $-0.21,0.095$ & 0.44 \\
Psychological growth & 0.31 & 0.048 & $-0.12,0.21$ & 0.57
\end{tabular}

$\mathrm{B}=$ unstandardized estimate; beta = standardized estimate. 
Figure 1. Conceptual model of the outcomes targeted by CALM therapy and their interrelationships in the context of advanced cancer.

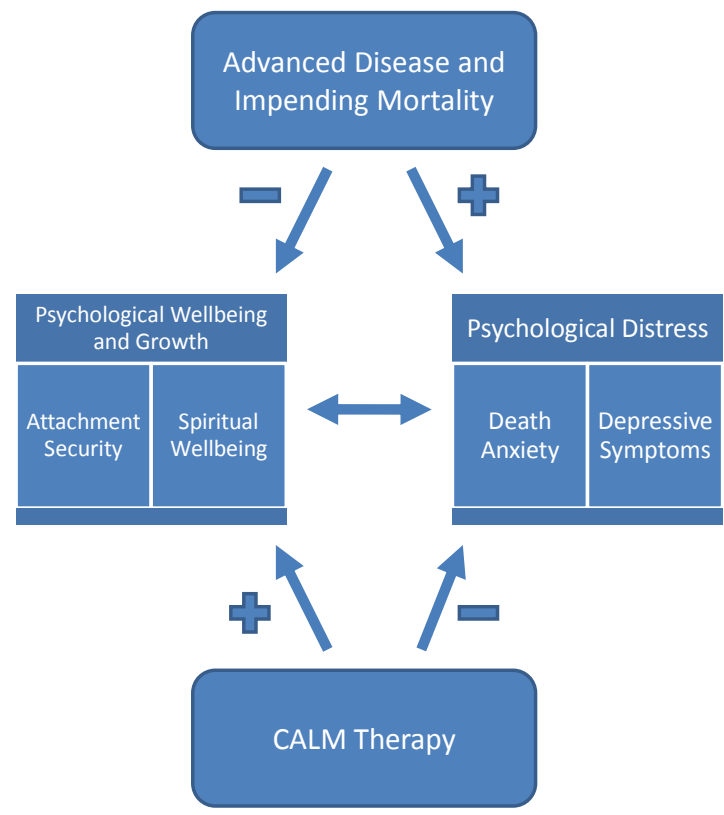

Note. Attachment security refers to confidence about the availability of supportive relationships and the capacity to make use of them for emotional support. Spiritual wellbeing refers to feelings of meaning, peace and faith. 
Figure 2. Patient flow diagram.

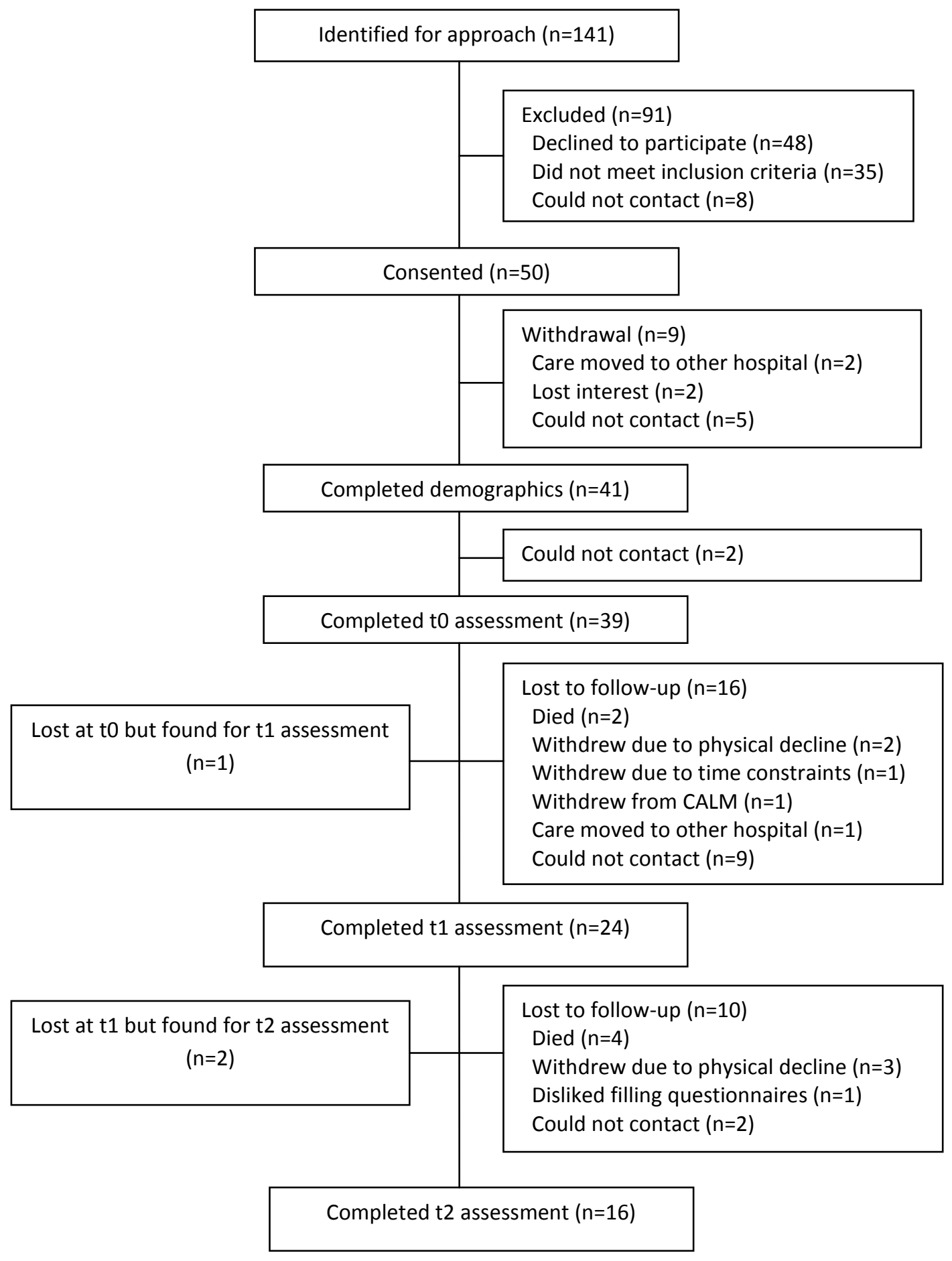

